\title{
Perspectivas sobre as estruturas não governamentais e a ação comunitária no apoio ao luto sadio em Portugal e o "Modelo Vivencial do Luto Sadio"
}

\section{Perspectives on non-governmental structures and community action in healthy bereavement support in Portugal, and the "Vivential Model of Healthy Grieving"}

\author{
José Eduardo Rebelo', Selma Lancman², Marina Picazzio Perez Batista ${ }^{3}$
}

http://dx.doi.org/10.11606/issn.2238-6149.v28i1p1-8

Rebelo JE, Lancman, S, Batista, MPP. Perspectivas sobre as estruturas não governamentais e a ação comunitária no apoio ao luto sadio em Portugal e o "Modelo Vivencial do Luto Sadio". Rev Ter Ocup Univ São Paulo. 2017 jan.-abr.;28(1):1-8.

RESUMO: As pessoas vivenciam lutos ao longo de suas vidas em decorrência de perdas pessoais profundas. A esmagadora maioria dos processos do luto são sadios, pois visam a superação da perda, por aceitação ou conformação, com a recuperação do homeodinamismo do corpo físico e mental. O luto pode ser trilhado com apoio formal, quando o enlutado sente a necessidade de partilhar a intensidade do seu pesar e os conflitos sentimentais emergentes e não encontra em sua rede de convívio a disponibilidade de uma escuta empática e sem censuras. O Conselheiro do Luto $(\mathrm{CdL})$ é o especialista que presta apoio ao luto sadio em âmbito comunitário. Em Portugal tem sido dada atenção à problemática do luto, com a fundação de instituições não governamentais científicas, de vigilância social, de formação para o apoio e de ação comunitária. O Modelo Vivencial do Luto Sadio foi desenvolvido a partir da experiência do apoio ao luto comunitário português e é um instrumento indispensável para a atividade do CdL. Um breve histórico sobre o apoio formal ao luto em Portugal, as instituições que têm como objeto as temáticas do luto, o surgimento e atuação do CdL e o Modelo Vivencial é apresentado no artigo, apontando-se para a necessidade de ampliação da rede de serviços de apoio ao luto disponível no país, através da integração na rede de ação social estatal.

DESCRITORES: Pesar; Morte; Estrutura dos serviços; Atitude frente a morte; Grupos de autoajuda; Apoio social.
Rebelo JE, Lancman, S, Batista, MPP. Perspectives on nongovernmental structures and community action in healthy bereavement support in Portugal, and the "Vivential Model of Healthy Grieving". Rev Ter Ocup Univ São Paulo. 2017 Jan.-Apr.;28(1):1-8.

ABSTRACT: People experience grief as a result of deep personal loss. The majority of the bereavement processes are healthy, because they seek to overcome the loss, by acceptance or conformation, with the recovery of the physical and mental body's homeodynamic. The process can be traced with formal support when the bereaved person feels to share the intensity of grief and the emerging of sentimental conflicts and does not find in their network the availability of an empathic and uncensored listening. The Counsellor for grief and bereavement (CdL) is the specialist who provides support for healthy bereavement at community level. In Portugal, attention has been given to grief, bereavement and mourning, with the foundation of non-governmental institutions, scientific, of social surveillance, training for support, and community action. The Vivential Model of Heathy Grieving was developed from the experience of Portuguese community bereavement support, and is a tool for CdL activity. A brief history of formal support for bereavement in Portugal, the institutions that deal with grief, the emergence and performance of the $\mathrm{CdL}$ and the Vivential Model is presented in the article, pointing to the need to expand the network for bereavement supporting services available, through the integration in state social services.

KEYWORDS: Death; Grief; Structure of services; Attitude to death; Self-help groups; Social support.

Os conteúdos apresentados neste artigo são resultados de entrevista realizada por Marina Picazzio Perez Batista, em junho de 2016, com o Prof. Doutor José Eduardo Rebelo. O contexto desta entrevista foi o estágio de pesquisa em Portugal, no âmbito de seu doutorado sanduíche, sob orientação da professora titular Selma Lancman. A entrevista foi gravada e transcrita. O texto obtido da transcrição foi corrigido, validado e complementado pelo Prof. Doutor José Eduardo Rebelo, resultando neste artigo teórico.

1. Professor Auxiliar com Agregação do Departamento de Biologia da Universidade de Aveiro, em Portugal, onde realiza pesquisas no GIECL - Grupo de Investigação em Estudos Científicos do Luto, que coordena. Fundador e presidente da APELO - Associação do Apoio à Pessoa em Luto; fundador e atual vice-presidente da SPEIL - Sociedade Portuguesa do Estudo e Intervenção no Luto; coordenador do OLP - Observatório do Luto em Portugal; fundador e presidente do EdL - Espaço do Luto.

2. Professora Titular do Curso de Terapia Ocupacional do Departamento de Fisioterapia, Fonoaudiologia e Terapia Ocupacional da Faculdade de Medicina da Universidade de São Paulo (FMUSP). Orientadora do Programa Ciências da Reabilitação da FMUSP. Email: lancman@usp.br

3. Terapeuta Ocupacional do Curso de Terapia Ocupacional do Departamento de Fisioterapia, Fonoaudiologia e Terapia Ocupacional da Faculdade de Medicina da Universidade de São Paulo (FMUSP). Doutoranda do Programa Ciências da Reabilitação da FMUSP. Email: marinapperez@usp.br

Endereço para correspondência: Espaço do Luto. Rua do Canto, 10 A. 3800-122 Aveiro, Portugal. Email: rebelo@ua.pt 


\section{INTRODUÇÃO}

$\mathrm{O}$ luto é definido como um processo de superação progressiva de vivências de desarmonia ocasionadas por uma perda pessoal profunda. Apesar de ser um evento natural da vida humana, em regra, o desenrolar das respostas íntimas às realidades da perda está associado a um intenso sofrimento físico e mental. $\mathrm{O}$ terapeuta ocupacional em sua prática profissional depara-se constantemente com perdas profundas em distintos contextos. Estas são frequentemente compartilhadas por usuários e familiares, ou são vivenciadas como lutos profissionais pela morte de pessoas atendidas. Considerou-se importante discorrer sobre o apoio ao luto sadio, estruturas formais existentes em Portugal e à luz do "Modelo Vivencial do Luto Sadio".

\section{Histórico das estruturas formais do apoio ao luto sadio em Portugal}

Até à década de noventa do século passado não existia apoio formal ao luto em Portugal. Nos finais daquele período, surgiu a Associação "A Nossa Âncora - Apoio a Pais em Luto", a qual finalizou suas atividades em 2013. Esta instituição desenvolvia ação comunitária, por meio de sessões de grupos de entreajuda de defilhados ${ }^{1}$ (pais em luto), as quais se espalharam pelo país ${ }^{2}$.

Em 2004, com o intuito de alargar o apoio ao luto aos principais tipos de perdas pessoais profundas, o Prof. Doutor José Eduardo Rebelo fundou a APELO Associação do Apoio à Pessoa em Luto $^{3}$, instituição que atualmente, por todo país, promove palestras, encontros, grupos e sessões individuais de apoio a pessoas e famílias em luto",4.

Como resultados deste processo, se observou aumento de espaços de partilha nos quais os enlutados sentem segurança em abordar o intenso sofrimento causado por perdas pessoais profundas ${ }^{* *}$. As pessoas encontram na APELO instrumentos que as empoderam no enfrentamento das pressões sociais exercidas por uma cultura que inibe a expressão pública dos sentimentos.
Apesar dos ganhos percebidos neste período, se identificou a necessidade de dar maior visibilidade à temática do luto. Assim, em 2010, o Prof. Doutor José Eduardo Rebelo liderou a fundação de instituições formais no âmbito do luto, nomeadamente a Sociedade Portuguesa de Estudo e Intervenção no Luto (SPEIL) ${ }^{5}$, o Observatório do Luto em Portugal (OLP) ${ }^{6}$ e o Espaço do Luto (EdL) que vieram preencher uma lacuna existente no país e proporcionar, em seu conjunto, a atenção qualificada aos enlutados a partir da formação de especialistas, bem como aumentar o escopo de conhecimento em Portugal acerca do tema.

A SPEIL ${ }^{5}$ é uma sociedade científica que a visa promover a investigação no luto, organizar e conduzir congressos científicos na área e formar especialistas para atuarem com enlutados. O OLP ${ }^{6}$ tem como função identificar o panorama do luto em Portugal, visando a ação científica, técnica e política neste âmbito. $\mathrm{O} \mathrm{EdL}^{7}$ é uma instituição vocacionada para a formação e supervisão específicas de especialistas no apoio ao luto saudável. $\mathrm{O} \mathrm{EdL}^{7}$ é, ainda, a sede do Grupo de Investigação em Estudos Científicos do Luto.

Um dos propósitos de fundação destas instituições era o de promover a formação de especialistas no apoio a enlutados, inexistentes até ao momento. Tendo em consideração as singularidades e exigências próprias dos lutos sadio e não sadio, considerou-se indispensável criar dois perfis de especialistas: o Terapeuta do Luto e o Conselheiro do Luto (CdL). O primeiro objetiva intervir junto a indivíduos que apresentam lutos psicopatológicos. Já o CdL tem como função a prestação do apoio empático a pessoas em luto sadio, a partir de: criação de um espaço fiável e seguro para a partilha do sofrimento do luto; disponibilidade para a escuta ativa e empática da partilha; normalização, sem censura, dos comportamentos do luto, particularmente, os socialmente condenados.

$\mathrm{O}$ apoio ao luto prestado pelo CdL não se restringe ao que é consequência da morte de entes queridos. Apesar desta ser a causa comumente associada ao luto, existem reações típicas e semelhantes quando a pessoa experiencia outras perdas pessoais profundas. As mais relevantes podem ser sintetizadas em cinco grandes grupos: $i$ ) separações de pessoas amadas, como divórcio,

\footnotetext{
* Neste mesmo período, o Prof. Doutor José Eduardo Rebelo publicou seu primeiro livro, pioneiro no país, sobre a temática do luto ${ }^{4}$.

** O Prof. Doutor José Eduardo Rebelo experienciou a perda da sua mulher, grávida, e suas duas filhas, mortas em um acidente rodoviário. Vivenciou luto intenso e não encontrando apoio adequado em Portugal, iniciou o que seu referencial teórico "Modelo Vivencial do Luto Sadio" coloca como a superação pela conformação. Este processo se deu por meio, primeiramente, de sua dissertação de mestrado sobre o tema do luto ${ }^{8}$, inovadora na área em Portugal, e, posteriormente, pela participação ativa na constituição de estruturas formais de apoio ao luto no país.
} 
Rebelo JE, et al. Apoio ao luto em Portugal e o "Modelo Vivencial do Luto Sadio”. Rev Ter Ocup Univ São Paulo. 2017 jan./abr.;28(1):1-8.

emigração e encarceramento; ii) perda de fantasia dos progenitores, como o nascimento de um filho deficiente ou um aborto; iii) dano ao amor próprio, por mutilação física, como uma amputação ou a ablação do seio; $i v$ ) desvalorização social ou profissional, como as causadas pela perda de emprego, rendimentos ou imagem pública; v) perdas socialmente não reconhecidas, como as de objetos e animais de estimação ou socialmente censuradas, como as de casais homossexuais e de parceiros de relações extraconjugais.

O princípio norteador para a ação do $\mathrm{CdL}$ é a existência de uma atividade de proximidade territorial às pessoas, famílias e comunidades em luto. A ação comunitária pode se dar por intermédio de sessões de apoio individuais e familiares, com um CdL, por grupos de partilha entre pessoas em luto, moderados por um CdL, ou por grupos de entreajuda, moderados pelos próprios enlutados, sendo, estes, supervisionados por um CdL.

O curso de CdLé ministrado no Espaço do Luto 7 por professores doutores universitários e inclui formação inicial e avançada. A primeira aborda a construção, manutenção e perda dos afetos, o "Modelo Vivencial do Luto Sadio", técnicas de comunicação empática com enlutados e a reflexão e experimentação a partir de metodologias ativas da ação do CdL. A formação avançada é realizada por meio de um estágio de observação de sessões de apoio ao luto realizadas por um $\mathrm{CdL}$ sénior, com posterior compartilhamento e reflexão crítica das observações e registros da vivência em espaço de supervisão .

A figura do CdL, apesar de bastante recente em Portugal, não é nova no Ocidente. Na Grã-Bretanha, por exemplo, surgiu em decorrência da devastação sofrida após a II Guerra Mundial, que acarretou um luto comunitário que abrangeu praticamente todas as famílias. $\mathrm{O}$ cenário assolador exigiu uma resposta pronta e eficaz, tendo surgiso uma estrutura global de apoio às perdas e ao luto.

Atualmente, em países como a Grã-Bretanha, Estados Unidos e Austrália, o apoio ao luto está bastante alicerçado. Observa-se grande incentivo financeiro do setor público para o trabalho comunitário promovido por associações. Contrariamente, em Portugal, o processo de estruturação do apoio qualificado ao luto sadio ainda é incipiente.

\section{O Modelo Vivencial do Luto Sadio}

O Modelo Vivencial do Luto Sadio, abreviado como Modelo Vivencial, é o referencial teórico que norteia a ação do CdL em Portugal. Este modelo, elaborado pelo Prof. Dr. José Eduardo Rebelo, busca compreender as reações do corpo, físico e mental, à privação definitiva ou temporária de alguém ou algo com uma importância decisiva na esfera afetiva da pessoa que sofre a perda.

O Modelo Vivencial conceitua que na ocorrência de uma perda pessoal profunda se colocam em marcha reações automáticas singulares de resposta ao pesar, ou seja, ao desequilíbrio intrínseco dela decorrente. A privação da pessoa alvo da ligação afetiva provoca insegurança básica, um medo instintivo, ao nível da sobrevivência individual.

Conceitua-se o pesar como os elementos experienciados pelo enlutado de ameaça à sua existência, de caráter não consciente, que prostram o indivíduo para o desalento e a solidão. O luto é uma resposta sadia ao pesar, já que visa extingui-lo, por meio de um processo que se desenrola em um período determinado de tempo que potencializa as competências naturais da pessoa para enfrentar adversidades. O nojo é o vértice cultural do triângulo de resposta à perda, entendido como os rituais que determinam a aceitação e rejeição social dos comportamentos do enlutado.

O luto, entendido como um processo de superação progressiva de vivências de desarmonia ocasionadas por uma perda pessoal profunda, é o caminho próprio necessário para reencontrar um equilíbrio homeodinâmico. Face à perda sofrida, durante o luto, a pessoa é conduzida para a reconquista de um bem viver, que se traduz, na essência, pela segurança física e mental do indivíduo.

No percurso do luto há quatro dimensões racionais elementares com as quais o enlutado tem necessidade de lidar, que se podem designar por Quadratura da Comprovação da Perda: i) tomar consciência da irreversibilidade da perda; ii) compreender o que realmente perdeu com a perda; iii) identificar quais são as suas competências para lidar com o luto e dar continuidade à vida sem a pessoa perdida; $i v$ ) perceber como é possível vivenciar o cotidiano na ausência do que se perdeu. A assimilação destas dimensões, embora se possa processar com alguma lentidão, pelo menos mais demorada do que é ansiada pelo enlutado, é natural e evidencia-se como decisiva para a superação sadia da perda. A Quadratura da Comprovação da Perda leva a pessoa em luto a emergir da solidão em que a perda a tinha mergulhado, devolvendo-lhe a plenitude de suas competências emocionais. $\mathrm{O}$ enlutado sente-se habilitado a acostumar-se a conviver com a inexistência de resposta para a questão mais complexa e difícil que o pesar lhe impôs: "Porquê a mim?".

Para melhor compreender o luto sadio, o Modelo Vivencial considera que o enlutado experiencia Vivências Globais (VG), impulsionadas por emoções primárias, Vivências Específicas (VE), incluídas nas primeiras, 
Vivências de Detalhe (VD), correspondentes aos pormenores das ligações afetivas, e Vivências de Transição (VT). As múltiplas vivências do luto podem ser de sujeição ou de superação em relação à perda.

As VG podem ser do Choque e Descrença, em que o enlutado se encontra sujeito à perda, e do Reconhecimento e Superação, em que a realidade se the impõe. As VG do Choque são acionadas pelas emoções primárias de surpresa e repulsa.

Assim, no que tange à VG do Choque, se identifica que face à notícia da perda, a pessoa experiencia uma resposta orgânica poderosa que cinde o real (por exemplo, a pessoa vê o cadáver) do emocional ("isto não pode estar ocorrendo!"). A ligação que unia as duas pessoas era muito forte e fundava-se na sobrevivência e perenidade da sua essência, ou seja, na luta pela sua própria vida e/ou no assegurar de um legado para além do limite natural da sua existência. A espécie humana desenvolveu-se para não abdicar de si própria pelo que, face a uma perda profunda, que põe em risco o indivíduo ou a sua capacidade de sucessão, o corpo, físico e mental, reage espontaneamente no intuito de preservar seus alicerces abalados.

As VE do Negar da perda, de sujeição à perda pela surpresa emocional da ocorrência, são desmentidas pelas VE do Verificar da realidade, de superação da perda, por meio da percepção consciente das provas da morte ou das outras causas de perda. A energia metabólica desviada para a fixação na contrariedade dos fatos é tão elevada que esgota o enlutado. A repulsa, que caracteriza VE do Torpor, de sujeição à perda, desenrola-se no intuito da pessoa recuperar, através de VE do Ânimo, de superação, um equilíbrio, ainda que débil, para defrontar as exigências da privação e se opor à verdade que as exéquias denunciam.

O processo do luto decorre entre uma semana e um mês, as provas da realidade da perda são tão fortes e a energia para contrariar a realidade é tão dispendiosa que a pessoa se vê forçada a baixar suas barreiras de recusa. Sem a capacidade de bloqueio da privação, a emoção primária do medo, expressa na angústia sobre a continuidade da existência, faz emergir as VG da Descrença, de sujeição à perda.

$\mathrm{Na}$ VG da Descrença distinguem-se as VE da Busca da pessoa perdida, de sujeição, que colidem com as VE do Desencontro do ente querido, de superação. O enlutado, no intento de manter o ente querido "vivo" dentro de si, procura recorrentemente guardar toda a dimensão da, outrora, fonte de felicidade. As fantasias que tinha gerado em relação ao amor da sua vida, as memórias agradáveis das percepções, como as imagens, os cheiros, a delicadeza da pele, os objetos e roupas que usava, as pessoas com quem convivia, os espaços que percorria e o tempo, através das efemérides, são detalhadamente calcorreadas em ânsia de sinais que contrariem a perda.

Cada VE da Busca, cada caminho de desassossego percorrido pelo enlutado no desejo de reunir os estilhaços do belíssimo todo que the conferia segurança ou era um legado esbarra estrondosamente com o vazio. Qualquer VE do Desencontro encontra uma de duas saídas possíveis, a VT da Frustração ou a VT do Desespero, ambas, de transição para a VG do Reconhecimento.

Assim, se observa que a imposição do passado no cotidiano do enlutado e o desejo intenso de a ele regressar, sujeição à perda, contrasta com a assimilação do presente e a superação dos laços afetivos que uniam o enlutado ao ente querido. A assimilação da irreversibilidade dos inúmeros detalhes da perda assola o enlutado. A VT da Frustração origina VE da Raiva e VE da Tristeza e a VT do Desespero ocasiona VE da Culpa e VE da Depressão. Qualquer uma destas vivências de sujeição à perda ou encontra uma via de superação ou, se tal não acontece, por meio de VT da Esperança ou de VT do Anseio retornam à VG da Descrença, reentrando no ciclo das VE Busca-Desencontro.

Quando o enlutado sente que se esgotou uma via de tentativa de retorno do fruto do seu amor, o vazio afetivo agiganta-se de forma insuportável. A elevada tensão negativa acumulada com a ausência insuportável tem de ser libertada, de forma condicionada e progressiva, para não transbordar os limites de sanidade física e mental. Os picos do conflituoso desassossego causados pelas VT da Frustração ou do Desespero, ao ver-se obrigado a abdicar da pessoa amada, em consequência da VE do Desencontro, são dissipados pela expressão episódica de vários sentimentos.

Quando as VE da Raiva são adequadamente orientadas para o morto, a verdadeira causa do sofrimento da perda, por meio das VE da Direção da Raiva, sobrepõe-se a superação do desenlace do pormenor afetivo que, no momento, provocava aflição. Nem sempre é possível dirigir para o ente querido a agressividade provocada pelo súbito vácuo de afeição, dado o receio de amplificação do próprio sofrimento $\mathrm{e}$ a pressão social sobre a demonstração de um sentimento comumente associado ao egoísmo. O desvanecimento da intranquilidade tem de ser indireto e os familiares e amigos, a nível mais próximo, ou os profissionais de saúde, forças de segurança, políticos, guia espiritual e Deus, de modo mais alargado, são os alvos frequentes da ira do enlutado. As VE da Tristeza, também surgidas em explosões incontroláveis, de começo, vão encontrando, gradualmente, vias de superação, com VE da Tristeza 
Rebelo JE, et al. Apoio ao luto em Portugal e o "Modelo Vivencial do Luto Sadio”. Rev Ter Ocup Univ São Paulo. 2017 jan./abr.;28(1):1-8.

Dissipada. Sempre que as VE da Raiva ou da Tristeza não superam as VT da Frustração, o enlutado encontra em VT da Esperança um sentimento expectante de recuperar a vastidão de afeição que ainda não se encontra preparado para abandonar.

As VE do Desencontro podem provocar outras reações muito intensas no enlutado, expressas em VT do Desespero. As VE da Culpa e da Depressão são respostas aflitivas encontradas por quem experiencia o afastamento, por vezes definitivo, de alguém amado. A culpa pela morte é irracional, correspondendo ao sentimento de avaliação negativa de atitudes que foram tomadas ou que não foram assumidas em relação ao ente querido. A via da superação surge com as VE da Culpa Responsabilizada, quando é possível converter a subjetividade moral em responsabilidade objetiva dos atos.

No processo do luto sadio, o abatimento resultante da luta titânica e intransponível contra o deserto afetivo ocasionado pela perda, a derrota ímpar forçada pela vida, origina VE da Depressão, revelada por estados de baixa autoestima e desinteresse pelo prazer do que rodeia a pessoa. Ao contrário dos estados depressivos doentios, no luto aqueles sentimentos são episódicos e não continuados, pelo que, assomados como instantes de despedida, devem ser experienciados, sendo prejudicial a sua camuflagem com fármacos. A via de superação dos episódios vivenciais depressivos é realizada através das VE da Depressão Alentada. Sempre que as VE da Culpa e da Depressão não são superadas, as VT do Anseio encaminham o enlutado para o ciclo da VG da Descrença.

Em um complexo processo vivencial que decorre em um tempo relativo, menos ou mais prolongado, consoante o grau de afeição que ligava o enlutado ao ente querido, os incontáveis laços afetivos vãose desfazendo, um agora, outro mais adiante, em um movimento constante de diminuição progressiva do pesar e de cicatrização das feridas provocadas pela perda. As VG da Superação, animadas pela emoção de fundo do bem-estar, conduzem a uma nova homeodinâmica, a um equilíbrio saudável do corpo, físico e mental, para enfrentar o intrincado cotidiano.

O Modelo Vivencial estabelece que a evolução do luto sadio, mesmo o complexo, proporciona a assimilação da multiplicidade existencial e experiencial da perda. As diferentes ligações afetivas dão lugar a duas vias alternativas das VG da Superação: VE da Aceitação ou Conformação. Admite-se que no luto por morte da pessoa amada a superação das particularidades vivenciais pode revelar-se menos intensa e mais simples de se lidar quando a perda é expectável no curso da vida, ou seja, quando existe uma elevada previsibilidade natural, como na morte do pai ou do avô muito idosos. Na sucessão normal do devir, entre o passado, o presente e o futuro, a privação física do passado, e sua conversão em memórias doces e suaves, pelas VD da Desvinculação, são acontecimentos de assimilação relativamente breve e serena. Muito embora o luto, com toda a sua dor, não possa ser evitado, pela essência intrínseca da ligação afetiva, a perda é superada pelas VE da Aceitação.

Persistindo na metáfora cronológica, a conjugalidade simboliza o presente, as escolhas mútuas de subsistência, por meio da preocupação recíproca, e do legado, por intermédio da concepção de filhos e do seu cuidar. A perda do cônjuge pode ser interpretada como a privação de uma certa atualidade, também expectável. Os parceiros, ao se unirem numa relação amorosa, reconhecem, implicitamente, que um dia, que desejam ser o mais distante possível, um irá se despedir definitivamente do outro. A morte gera um luto, mas o cônjuge em luto encontra nas VE da Aceitação o caminho para o reencontro do seu bem-viver. No processo deste tipo de luto diversos aspectos influenciam o experienciar progressivo do desapego, como o momento e circunstância da morte e as condições sociais e econômicas em que fica o sobrevivo9.

Ressalve-se, no âmbito da perda da conjugalidade, a distinção devida entre os conceitos de cônjuge em luto e de viúvo. Por cônjuge em luto entende-se o homem ou a mulher que perdeu a esposa ou o marido, por morte, e que ainda não deu o último passo de transposição das VG da Superação. Já viúvo/viúva é o estado civil do homem/mulher a quem morreu o cônjuge e que, assim, se mantém, independentemente de ter ou não superado o seu luto, até celebrar novos laços matrimoniais ou até sua própria morte. Assim, na abordagem da temática do luto na conjugalidade, a designação inequívoca e, portanto, adequada, para o elemento sobrevivo do casal, é o termo cônjuge em luto ou viúvo(a) em luto e não, simplesmente, viúvo.

Encerrada essa ressalva, retoma-se a expectativa de cronologia das perdas para referir que um dos lutos mais dolorosos e prolongados, que se estende, em regra, pelo resto da vida, é o que decorre da perda de um filho. O defilhar ${ }^{1}$, lexema introduzido pelo Prof. Doutor José Eduardo Rebelo, embora seja sadio, porque visa uma nova homeodinâmica do defilhado, é bastante complexo. Este tipo do luto atinge o âmago da essência humana ao interromper o principal desígnio de qualquer espécie viva: o de preservá-la no planeta por meio do legado de seus genes entre as gerações. Conviver com a perspectiva de 
quebra da função instintiva da espécie exige um esforço bastante considerável. Aos instintos acrescentam-se muitas expectativas individuais e sociais que a pessoa deposita no filho, tais como o bem, como valor supremo; perspectivas de realizações futuras; investimento para a continuidade da vida; desejo de deixar um legado, e, em alguns casos, assegurar apoio na velhice, fase da vida em que possivelmente os pais se encontrarão mais vulneráveis ${ }^{1}$.

Ao contrário dos lutos por perda do passado ou do presente, em que as VE da Aceitação constituem o corolário do processo do luto, a perda do futuro pela morte do filho é inaceitável. Apesar do defilhado ter de lidar com seu luto, eventualmente, até ao fim de sua vida, as VE da Conformação são compagináveis com o alcançar de um bem-viver. A perda do filho é assimilada pelas VD da Continuidade, que podem proporcionar ao defilhado memórias suaves, mas agridoces, sobre o ensaio fatalmente interrompido do seu legado à natureza e à humanidade ${ }^{10}$. A morte de um irmão gémeo univitelino gera, no enlutado, reações semelhantes ao defilhar, tendo em consideração a perda da sua identidade genética.

As ligações afetivas que as pessoas estabelecem entre si são pares e biunívocas, ou seja, são exclusivas aos dois indivíduos nela envolvidos e estão sempre associadas a expectativas. Aquando da perda de um dos elementos envolvidos no relacionamento, o luto é vivido incondicionalmente em solidão. No defilhar, por exemplo, o pai e a mãe, pelas suas especificidades biológicas em relação ao procriar e pelo que aprenderam a esperar de um filho, apesar de ambos experienciarem o luto pela morte de uma única pessoa, desenvolvem seus processos singulares. A não compreensão entre o casal de que os caminhos do luto são obrigatoriamente diferentes, por serem idiossincráticas, e que as distintas manifestações não traduzem maior ou menor sentimento pelo filho morto, podem levá-los a experienciarem uma nova perda: a do divórcio.

Apesar dos sentimentos de intenso sofrimento com que o enlutado se vê confrontado durante o luto, o rumo seguido é unidirecional e irreversível: o da superação. O ser humano é constituído para, de forma instintiva, enfrentar e superar as maiores adversidades, particularmente, as perdas pessoais profundas. A privação de um ente querido é um fator de insegurança temporária do enlutado, que deixa marcas indeléveis, raramente traumáticas, no luto sadio. $\mathrm{O}$ sentimento em relação à perda também se transforma com a experiência das vivências do luto, amenizando-se aos poucos e tornando-se progressivamente menos aflitivo e ansioso, até que se esfuma, com VE da Aceitação, ou permanece em uma latência suportável e não agressiva, com as VE da Conformação.

$\mathrm{Na}$ imensa maioria dos casos de perda pessoal profunda, mesmo os complexos, os enlutados têm capacidade para a sua superação. O processo do luto pode não seguir uma evolução sadia nas condições seguintes: a ocorrência de situações traumáticas sérias associadas à perda; a propensão do enlutado para manifestar algum transtorno psiquiátrico frente a um contexto que o sujeita a grande vulnerabilidade; quando o enlutado padece de um transtorno psiquiátrico que o fixe em uma das Vivências Globais do luto. Os cerca de quarenta pequenos ou grandes lutos que o homem vivencia no decurso de sua vida são de natureza saudável e podem ser apoiados no âmbito da ação comunitária.

\section{A ação comunitária no apoio ao luto}

A dinâmica do apoio ao luto no âmbito comunitário é realizada de modo abrangente, abarcando distintos contextos, tais como a $\mathrm{APELO}^{3}$ e instituições externas que solicitam o apoio, como centros de saúde, escolas, empresas e órgãos públicos.

O apoio ao luto em contexto escolar é alvo de atenção particular na atividade comunitária da $\mathrm{APELO}^{3}$, uma vez que se reconhece que perturbações em sala de aula, com o desafio do poder simbolizado no professor, ou o bullying aos colegas efetuado por um aluno que, inesperadamente, se tornou muito agressivo, pode ser decorrente da vivência de lutos. Observa-se frequentemente a falta de apoio que a escola provê à criança em luto e a ausência de preparo dos professores para esta problemática, apontando para a necessidade da construção de espaços de partilha que acolham estas vivências.

Também no que se refere ao apoio comunitário, vale colocar que as instituições sociais, os valores morais e hábitos culturais condicionam o luto individual, familiar e comunitário, ao impor leis e normas subjetivas para a expressão das vivências do luto. A licença de nojo, por exemplo, é um período muito curto para certos tipos do luto. A readaptação ao cotidiano laboral que anteriormente o enlutado desempenhava exige um tempo muito superior àquele a que legalmente lhe é facultado. Comumente observa-se uma diminuição em sua produtividade laboral, seja pela baixa eficácia com que desenvolve suas tarefas, seja pelo absentismo, o que não é compreendido pelo empregador e colegas de trabalho. O enlutado, ao confrontar-se com esta contradição, muitas vezes precisa negligenciar a vivência de um sofrimento necessário. Neste contexto, a realização de processos mais eficazes 
Rebelo JE, et al. Apoio ao luto em Portugal e o "Modelo Vivencial do Luto Sadio”. Rev Ter Ocup Univ São Paulo. 2017 jan./abr.;28(1):1-8.

de apoio, focado nas necessidades do enlutado tornam-se uma questão de relevância.

Ainda no que tange ao apoio ao luto em âmbito comunitário vale conceituar que é a pessoa em luto quem deve procurar auxílio, caso sinta essa necessidade de ajuda. A atitude e motivação para a busca do apoio são, por si, um passo de superação. Somente a pessoa que vive o sofrimento da perda é quem sabe quando tem condições para pedir o apoio, competindo a quem a rodeia, dar a conhecer que o apoio existe. Entre as demandas singulares que levam a pessoa em luto a procurar apoio, incluemse: sua personalidade, as condições em que ocorre o fenômeno causador da privação do ente querido, a pressão social repressora da expressão de sentimentos profundos de sofrimento e a limitada ou ausente rede de apoio.

O momento para o pedido do apoio ao luto no enquadramento do processo não é aleatório. O enlutado, mergulhado nas VG do Choque recusa liminarmente a perda e, em consequência, falar sobre o luto pode ser considerado como ofensivo. Conhecendo as reações ativas do corpo no intuito de manter um equilíbrio possível, ainda que muito precário, insistir com o enlutado sobre a realidade da privação que acaba de sofrer é desestabilizador da vulnerabilidade em que se encontra. Qualquer eco, ainda que tênue, sobre os fatos da perda obrigam a pessoa em luto a redobrar a tensão de defesa, com o aumento do dispêndio de energia metabólica, no intuito de assegurar a insistência necessária da proximidade viva do ente querido, como garantia de sua própria sobrevivência.

A exaustão provocada pelas VE do Negar e pelo sofrimento das VE do Verificar obrigam o enlutado a baixar barreiras em relação à perda, sendo, então, assolado pela emoção primária do medo. O desassossego que emerge com as VG da Descrença revela-se no temor sobre um cotidiano definitivamente inseguro, que coloca em risco a própria existência. A demanda pelo apoio é muito frequente neste momento do processo do luto porque o enlutado tem necessidade de partilhar os sentimentos e comportamentos, por vezes, inusitados e anômalos às regras de conduta sociais.

$\mathrm{Na}$ maioria das perdas é comum o enlutado encontrar nas pessoas que o rodeiam - familiares, amigos e/ou vizinhos - o apoio adequado às suas necessidades. Sempre que existe uma estrutura informal de apoio, com pessoas com disponibilidade para ouvir incondicionalmente a pessoa em luto sem censurar seus atos, estão criadas as condições para um processo do luto com suporte apropriado. Porém, nem sempre o contexto do apoio se encontra disponível, por razões distintas, nas quais se destacam: a insuficiência de uma rede relacional; os membros da rede terem dificuldade em lidar com a perda; os elementos da rede também se encontrarem diretamente afetados pela mesma perda, experienciando seus próprios processos do luto e não apresentando condições emocionais para auxiliar o outro.

Quando não existe abertura para a partilha e suporte eficaz, o enlutado pode sentir necessidade de procurar um apoio institucional especializado, que em Portugal é prestado pelo CdL. Nem todas as pessoas, contudo, sentem necessidade deste tipo de apoio, porque como apontado anteriormente, o luto é um processo normal da vida e o ser humano está constituído para superar grandes obstáculos, como os decorrentes de uma perda pessoal profunda. Desse modo, é esperado que quando o enlutado não procure apoio, este vivencie seu processo do luto sadio sozinho e acabe por superá-lo.

Qual é, então, a importância da atuação do CdL? Reconhece-se que quando o enlutado dispõe de um lugar de partilha para o que o aflige na perda facilita-se uma superação do luto mais breve e, consequentemente, menos sofrida. Embora o enlutado tenha capacidades para encontrar seu próprio caminho, a dificuldade de distanciamento pessoal em relação às explosões sentimentais e comportamentais a que o luto o compele torna mais emaranhada e lenta a superação de certos obstáculos. O CdL cria um espaço confiável e de segurança para a partilha, o que se constitui como um meio determinante para que o enlutado consciencialize e afirme seu próprio trajeto do luto no sentido da superação da perda. O caminho do luto, necessário ao esvaziamento do pesar, é a sucessão de reações incontornáveis à pessoa que sofre uma perda profunda, que pode ser trilhado em ritmos qualitativamente distintos, quando é apoiado ou experienciado em completo isolamento.

No apoio formal, o CdL assume-se em relação ao enlutado como um eco de consciencialização do processo do luto por ele experienciado. Ao longo das diferentes sessões, busca devolver ao enlutado as Vivências do Detalhe, com prevalência para as de Superação da Perda, por ele verbalizadas durante a partilha. Esta estratégia tem como finalidade auxiliar o enlutado a fixar os pequenos passos dados em seu percurso, no sentido da superação de cada desenlace afetivo que emocionalmente se vai processando em direção a um novo equilíbrio sadio. No decurso das diferentes sessões do apoio, intenta-se que o enlutado extinga seu pesar ao verificar que, paulatinamente, mas de forma constante, as Vivências da Sujeição à Perda diminuem, sendo compensadas pelo alargamento das Vivências da Superação. 
A comunicação com o enlutado deve merecer especial atenção e cuidado, pelo que é dada elevada relevância a este tema na formação do CdL. Socialmente, as pessoas que lidam com enlutados têm dificuldade em conviver com o sofrimento por eles manifestado. Condoídos com a dor, por razões cívicas formais, solidariedade, tentativa de consolo ou ação profissional, as pessoas sentem necessidade de expressar seus pêsames, usando uma narrativa em que são frequentes frases inoportunas e consideradas ofensivas por quem as ouve. A nível profissional, os deslizes na mensagem ao enlutado ocorre pela ausência de formação especializada a quem lida com esta problemática.

O CdL, respeitando o tempo da narrativa do enlutado, busca identificar as Vivências da Superação da Perda, as quais lhe são imediatamente devolvidas para que delas tome consciência e sobre elas reflita. Esta estratégia visa auxiliar a pessoa em luto a determinar qual direção considera mais confortável para percorrer o caminho de seu luto sadio.

$\mathrm{O}$ CdL não prescreve ao enlutado regras ou tarefas para lidar com o seu processo. Prover suporte para que o enlutado possa melhor lidar com os conflituosos e inseguros sentimentos resultantes da privação a que se vê sujeito é a principal função do CdL, com destaque para o apoio à descoberta que ele vai fazendo das estratégias que considera mais adequadas para si no trilhar de seu caminho singular do luto. A ligação do enlutado ao ente querido era única e, igualmente, particular.

\section{REFERÊNCIAS}

1. Rebelo JE. Defilhar: como viver a perda de um filho. Alfragide: Casa das Letras; 2013.

2. Rebelo JE. Importância da entreajuda no apoio a pais em luto. Análise Psicológica. 2005;23(4):373-80. doi: 10.14417/ap.555.

3. Associação do Apoio à Pessoa em Luto (APELO). Disponível em: http://apelo.pt

4. Rebelo JE. Desatar o nó do luto. 3a ed. Cruz Quebrada: Casa das Letras; 2007.

5. Sociedade Portuguesa de Estudo e Intervenção no Luto (SPEIL). Disponível em: http://speil.pt

\section{CONSIDERAÇÕES FINAIS}

O homem sofre perdas pessoais ao longo de sua vida, resultando em reações de intensidade mais ou menos profundas, que visam superar as privações a que se viram submetidos e alcançar um equilíbrio sadio do corpo, para bem-viver. A sociedade contemporânea marginaliza as expressões de contrariedade, isolando quem necessita partilhar o sofrimento imposto pelo pesar. Por outro lado, o modo intensivo e rápido com que o cotidiano é vivido na atualidade, dificulta ao enlutado a possibilidade de usufruir do tempo apropriado para a assimilação de todas as questões que envolvem o pesar.

O luto é uma questão de saúde pública e a atenção específica das entidades governamentais na criação de estrutura de apoio aos enlutados é neste contexto uma necessidade. Considera-se que a expansão do apoio ao luto favoreça o alívio das pressões sociais sobre a pessoa, família e comunidade enlutada, permitindo-lhes superar suas perdas com menor sofrimento, maior brevidade e melhor aceitação pública.

A APELO tem contribuído para chegar mais perto de quem necessita partilhar o sofrimento decorrente de suas perdas. OCdL, embasado no Modelo Vivencial do Luto Sadio, apoia o enlutado a construir, com segurança, um caminho idiossincrático para alcançar a superação da sua perda. O suporte de confiança propiciado pelo CdL permite abreviar o tempo do luto e diminuir a intensidade do sofrimento.

6. Observatório do Luto em Portugal (OLP). Disponível em: http://olp.speil.pt

7. Espaço do Luto (EdL). Disponível em: http://espacodoluto.pt

8. Rebelo JE. Contributos para o estudo do processo de luto [Dissertação]. Porto: Psicologia da Saúde e Intervenção Comunitária, Universidade Fernando Pessoa; 2003. Disponível em: http://olp.speil.pt/images/lutoteca/4_dissert/ Rebelo2002_Mestrado.pdf.

9. Rebelo JE. Amor, luto e solidão. Lisboa: Casa das Letras; 2009.

10. Rebelo JE. Viver o luto: a morte dos próximos (pais e filhos). In: Brito JHS. O fim da vida. Braga: Publicações da Faculdade de Filosofia, UCP; 2007. p.155-72. 